\title{
The challenges of stem cell research in Nigeria
}

\author{
Clara Agbedia*, Oshegbo Godwin \\ *Senior Lecturer, The Department of Nursing Science,Delta State University, Abraka, Delta State Nigeria. \\ Assembly Pastor, Okerore Baptist Church Eku. Delta State. Nigeria. \\ *Corresponding author E-mail: oniovo4life@yahoo.com
}

\begin{abstract}
Many patients and their families, have great expectations that Stem cell therapy could be the cure for a host of devastating diseases such as Parkinson's disease, Alzheimer's dementia, diabetes, multiple sclerosis, burns, etc. As stem cell research gains ground in Nigeria, it is appropriate to explore the issues surrounding the use of human embryos for stem cell research and its implication from a nursing perspective. In this paper the socio-political implications of the use of embryonic stem cell research was addressed. The nursing, medical and legal literature (both print and electronic) related to Stem cell research and therapy were evaluated and the main ethical issues raised by the destruction of human embryos were examined.

There must be a public discussion/debate on the benefits including its cost implication. Nigerians must evaluate the appropriateness of stem cell technologies within their own national contexts and prioritize which applications are the most promising for improving their health.
\end{abstract}

Keywords: Advocacy, Debilitating Medical Conditions, Embryonic, Ethical Issues, Stem Cell Research (ESR), Nurses.

\section{Introduction}

Stem cell research has undoubtedly created a huge tension that has led to an extensive debate among scientists, religious groups and politicians since it began 25 years ago, when in vitro fertilization (IVF) techniques were introduced [1] It is frequently argued that embryonic stem cell research (ESR)using human embryos will lead to a cure for many devastating diseases such as Parkinson's disease, Alzheimer's dementia, diabetes, multiple sclerosis, burns, etc [2] It is somewhat of an irony that the discovery of cells with such a tremendous potential for improving and prolonging lives, should bring with it some intractable questions about the value of life itself. Here, values are understood as the deeply held and sometimes unarticulated ideas and principles which a society and its individuals hold, and these values, ideas and principles move societies/communities to respond, either positively or negatively, to possibilities [3].As a consequence, two radically opposed groups have emerged in society; those who advocate absolute respect for human life beginning at conception, and those who do not.

Proponents of ESR [1,2,3]advocate that if the practice is endorsed, it could lead to acquisition of scientific knowledge about embryonic development, medical breakthrough for curing debilitating diseases such as Alzheimer's, Diabetes, Stroke, Spinal cord injuries, Bone diseases, etc., and screening drugs for pharmaceutical companies, instead of having to rely on animal models [2]. While these reasons may appear to have good intentions [5, 6] noted that there are still so many questions left unanswered? In an article released on October 22, 2006 by the Reuters UK News magazine, Steven Goldman and colleagues at the University of Rochester Medical Center in New York observed that injecting human embryonic stem cells into the brains of Parkinson's disease patients may lead to development of tumors. The researchers acknowledged that the transplant did help the rats for a while but started developing into tumor as a result of their pliability. This is one of many reasons why stem cell technology has been opposed by concerned individuals and interest groups. ESR research is an emerging field of regenerative medicine and it grew out of findings by Canadian scientists, Ernest A. McCulloch and James E. Till in the 1960s. Its goal is not just to replace what is malfunctioning, but to provide the elements required for in-vivo repair, to devise replacements and to stimulate the body's intrinsic capacities for regeneration.

Meanwhile, Nigeria, as a developing country with a population of nearly 150 million, faces great challenges in terms of population growth, when compared to health care and agricultural developments. The life expectancy at birth has been reported to be 47 years in males and 48 years in females according to the 2008 National Demographic and Health Survey (NDHS) report. This is below the least developed countries (LDC) average age of 53 years. The disability 
adjusted life expectancy at birth is 38.3years [14]. Vaccine-preventable diseases along with infectious and parasitic diseases continue to take their toll on the health and survival of the population [7]. In addition, the prevention and treatment of various health threatening diseases needs to be improved. Nigeria's agricultural development is still rather poor in efficiency and quality, thereby exerting huge pressure on natural resources and the eco-environment. With the increase in rate of chronic, degenerative and acute diseases with its attendance economic and psychological costs on, stakeholders (government agencies, commercial enterprises, health providers, patients groups) in Nigeria must turn to innovative novelty and cost-effective means of treating diseases. As stem cell research gains ground in Nigeria, it is appropriate now to explore the ethical issues surrounding the use of human embryos for stem cell research and its implication from a nursing perspective. The question is that at what price would this projected practice be made viable and acceptable to the Nigerian populace?

Unfortunately some members of the general public are yet to be acquainted with what the stem cell story is all about. What therefore is stem cell?

\subsection{Stem cell}

Irving, [8] describes embryonic stem cells (ES) as an "essentially primordial cells of a human organism (i.e. a human being) which are capable of becoming all or many of the 210 different kinds of tissues in the human body." These cells have traditionally been defined as not fully differentiated yet (or, not fully determined yet) to be any particular type of cell or tissue. They range from "totipotent," i.e., almost totally undifferentiated and capable of becoming any tissue in the body (as in the early human embryo up to about the 4-day morula stage), to "pluripotent." Pluripotent stem cells are cells that can be reprogrammed into different cell lines using defined sets of growth factors. The genetic makeup of these cells can be artificially tweaked by scientists to create different cell lines and cell types as the cells act as precursors. Though this presents considerable hope in the treatment of different genetic disorders, this benefit is possible only at the cost of having to engage in either the morally contentious practice of human (therapeutic) cloning, or the morally contentious practice of using (and destroying) a large number of embryos to create a sufficient range of embryonic stem cell lines for organ banks. According to Robertson [2] the problem with the therapeutic use of embryonic stem cells is their immunological characteristics. Genetic manipulation will be needed to remove or suppress the immunological characteristics of the donor tissue. The other problem with their use is growth control. Transplanted cells may become growth control independent and form tumors in their host. Mechanisms for selectively killing the transplanted cells may be needed. In addition, the collection of peripheral blood stem cells and cells from the bone marrow is not only expensive but also painful.

\subsection{The alternative - Adult stem cell research}

Adult Stem Cell Research is thought of as the alternative. Adult stem cells (AS) are present in and drawn from bone marrow, brain and gut, and other tissues. Some of these stem cells have a capacity to differentiate into a limited number of different cell types, such as blood cells, muscles and neurons (i.e., they are multipotent). TheAdult Stem cells have not been shown to be pluripotent (able to differentiate into any cell-type) in the way that embryonic stem cells are. This limitation means that adult stem cells offer more limited potential benefits in regenerative medicine and gene therapy. Robertson, [2] argues that the harvesting and use of adult stem cells for biomedical purposes, however, avoids some of the ethically and biomedical problematic features of using embryonic stem cells. First, harvesting adult stem cells does not involve the destruction of embryos. Secondly, the use of Adult Stem cells also overcomes the immunological concerns associated with the use of embryonic tissue. Tissues grown from adult stem cells will be immunologically compatible with the person from whom the stem cells are harvested. This means that those tissues can be transplanted into that person without fear of the body rejecting them. Apart from being ethically less controversial, Adult Stem cells also have the advantage of being easier to handle than ES cells. Moreover, Adult Stem cells, unlike ES cells, do not seem to form cancerous masses when injected into adults [2,5].

\section{The debate}

The main ethical issue raised by ES cell research is the destruction of human embryos and the rights to life. The arguments given to justify the destruction of human embryos in research are based upon the 'developmental view that human embryos less than 14 days old cannot yet be considered individual organisms, on account of their being too rudimentary in development to have interests or rights, and thus should not be protected at the cost of legitimate and important scientific research [3]. According to Devolder [9] the embryo has none of the necessary characteristics of personhood e.g.: uniqueness, sentience, and the cognitive capabilities of consciousness, reasoning and self-awareness. This is a consequentiality approach, in that in determining the morality of actions, only the presumed consequences of 
performing such actions are considered. However, it is acknowledged that embryos have status greater than other tissue and thus deserve special respect. Such special respect for embryos requires good reasons to create, discard, and experiment on them, such as the need to treat infertility or carry out legitimate scientific research.

On the one hand, there is a strong opposition to the destruction of human embryos by different groups in society. Its proponents $[2,10]$ stress the equality of all human beings and the dangers of treating some differently from others. Their argument is that human embryos deserve the same respect as any other human being. This group of individuals thinks that a fertilized egg in the laboratory is a new human being with a unique human DNA, and if transferred to a uterus might develop those characteristics. O'Rahilly \&. Muller[10] state that fertilization is an important landmark because; a new, genetically distinct human organism is thereby formed. Therefore they opine that a blastocyst is not an ordinary cluster of cells as it contains a complete set of genetic instructions and the capacity for the epigenetic determinations needed to develop into a viable human being [2]. This position is strongly supported by many scientists, and ethicists, that reject the destruction of human embryos for research. They see destruction of embryos, like abortion of fetuses, as murder, as a sacrifice of the weakest link among us for the interests of others [8].

Biblically, human life begins at conception. According to the Bible human life originates as the image of God and through Him as the Sovereign creator (Gen 1:26; Isa. 45:18). The declaration of the Psalmist in Psalm 139:13-15 can be seen as an inspiration that was uttered in awe after a careful examination of the intricacies of the human life even at its earliest formation. It can also be argued that if the lack of certain personality traits would make embryos less than human, it could also be said that coma patients, senior citizens with degenerating disorders such as Alzheimer's disease, people with mental retardation, neurological diseases are less than human, or human beings as non-human persons. This is the deontology perspective.

The embryonic stem cell research, therefore presents us with a moral problem because it to bring into focus two fundamental moral principles utilitarian and deontology. The utilitarian principle enjoins the prevention or alleviation of suffering, and deontology principle enjoins us to respect the value of human life. The harvesting and culturing of embryonic stem cells has considerable potential to bring about remarkable potential benefits in the way of alleviating debilitating medical conditions. Thus, utilitarian perspective favors people needing cell therapy for ailments such diabetes, multiple sclerosis, burns, etc. On the other hand, there is a case to be made that the harvesting of human embryonic stem cells violates the second principle in that it results in the destruction of human life with value (i.e. human embryos). The question then is which principle ought to be given precedence in this conflict situation since the two principles apparently cannot simultaneously be respected in the case of embryonic stem cell research, should we permit destructive embryonic stem cell research because of its remarkable potential benefits? Or should we prohibit destructive embryonic research because it violates respect for the value of the embryo as the very beginnings of a possible human life? It is clear that each position in the ethical debate is grounded in fundamental moral values of life (human dignity, sanctity of life and autonomy) which are aimed at promoting a just and moral society.

\section{Benefits}

Until now, adults suffering from the congenital blood disorder sickle cell anemia, which causes organ damage and crippling pain along with an increased risk of stroke, had only two treatment options to help them cope with the disease: drugs and blood transfusions. A new stem cell transplant has proven to be revolutionary in reversing the effects of even the severe forms of this disease. Johns Hopkins University reported a high success rate bone marrow transplant in adults with nine out of ten patients showing no side effects from the treatment. The new stem cell procedure uses onefourth of the amount of radiation that is usually used to reduce the likelihood of transplant rejection. This significantly lessened exposure to radiation and results in faster recovery from the transplant process.

Research also conducted by Chicago-based Northwestern University suggests that stem cell therapy is successful in treating rheumatoid arthritis with the patient experiencing tremendous relief from her symptoms like morning stiffness and pain [12].Doctors and scientists have successfully used stem cells to help with oral problems like the decay of enamel on the teeth or to treat gums. Stem cells can also be used to create hepatocytes which make up most of the cells in the liver, Parkinson's disease, multiple sclerosis and several other medical conditions. Stem cell therapy has had positive results when used to regenerate the myelin lost in patients affected with multiple sclerosis. These therapies have the potential to help millions [12]

\section{Social and political implications}

Apart from the ethical issue on the use of human embryos for research, socio-political implications must be addressed to prevent societal exploitation. Since ES cell research does not concern only scientists, and the obvious fact that the 
medical facts therein are not widely known or understood by the general public, except that the use of ES cells could alleviate human suffering and promote better health conditions for patients, it is suggested that there must be a public discussion/debate on the benefits. The aim of the debate is to balance argument on the benefit of ESR to alleviate serious injury and debilitating disease, on the one hand, and, on the other, to determine whether the distribution of costs and benefits is actually fair and according to the principle of justice. The essence is the protection of the weak and the voiceless in the society. ESR should be evaluated within the context of Nigeria, including its cost implication.

In Nigeria, the Gross Domestic Product (GDP) is \$350 (USD) while the total per capita health expenditure is estimated at about \$54.61. The household is a major source of finance for the health sector and out-of-pocket expenditure which is about $70 \%$ [11] constitutes the major percentage contribution in health care. This means that half of the populations of Nigerians live below the poverty line and on about $\$ 1$ per day. Many are unable to pay for health services at the first port of call even before care is given. This situation has great implication on the individual, the healthcare provider and the society. The argument here is that, with the increasing social and economic burden of diabetes, heart disease, chronic kidney disease, and infectious diseases in the country, stem cell research and therapy should focus on how engineered immune cells could provide solution to these diseases. Other questions to be considered to ensure a fair debate are; will stem cell be an improvement over currently existing treatment options and have a clear impact on the health of Nigerians? Will stem cell therapy be safe and socially, ethically, and acceptable? Are there human and financial resources on the ground for ESR? How much investments have hospitals and physicians already made in this direction? The guiding idea for these criteria is that technologies have a good chance to be effective if they are appropriate to the needs, expectations and limitations of the surroundings in which they will be applied.

Additionally, it is important to pay some attention to conflicts of interest. Beauchamp \&Childress [1] argues that when science is driven by profit maximization, ethics is often relegated into the background. Ethics are then regarded not as guidelines for good research, but rather as an obstacle to be overcome in the search for profit. However, as highlighted in the 2005 report of the United Nations Task Force on Science, Technology, and Innovation, domestic innovation must be targeted towards local health needs. Though communicable diseases constitute major causes of mortality and morbidity in the country, [6] there are reasons to believe that non-communicable diseases such as hypertension, diabetes mellitus, coronary and rheumatic heart disease, sickle cell disease, cancers, mental health, blindness, and stroke, represent an increasing share of Nigerians' burden of disease. Stem cell research should therefore focus on preventive and treatment options. Nigerians must evaluate the appropriateness of stem cell technologies within our own national contexts and systematically identify and prioritize which applications are the most promising for improving the health of Nigerians. In all it is important that ethical assessment of stem cell research projects must be done to ensure that the basic clause of the Helsinki Declaration (respected and the well-being of the human subject) is adhered to:

\subsection{Building capacity}

There is a great and urgent need for capacity-building of health care professionals in ESR. In building build capacity in ESR, Nigeria must seek help from countries that have shown higher levels of achievements in ESR and stem cell therapy. The Brazilian and Indian government have invested millions of dollars on clinical trial of autologous stem cell therapy for the treatment of heart diseases; India especially is generating huge revenue from stem cell therapy [14]. Brain drain in Nigeria is making a bad situation even worse as health care professionals especially nurses are increasingly being lured by employment opportunities in more affluent countries. Additionally, there is the issue of "the internal brain drain," i.e. health professionals abandoning the public health sector for more lucrative and careerenhancing positions in the private health sector, foreign-funded health research projects, banks and medical positions within non-governmental organizations. Given this conundrum, a talent hunt strategy is a must to attract more talented young people to devote themselves to this area of life science.

\subsection{The nurse as an advocate}

Embryonic Stem Research is about rights to life, longevity and health; nurses must understand the biology of the process of ESC research and its ethical issues. Understanding the scientific aspects will help nurses to give patients a clear picture of the associated processes as well as counsel those whose health will be improved and those who will not benefit from ESR. To become adequately informed for this advocacy role, nurses must become involved in the global issues of the day. Familiarity with local and national political systems is also needed. This will help nurses to clarify the constraining and enabling factors that might influence the use of ESR in health care and its implication to nursing practice. However, the advocacy role can lead to a situation where nurses have two competing accountabilities; the patient/the communities and the government. The two must be reconciled so that government policies are aligned with public needs. Based on this knowledge, nurses must seek more viable individual and collective roles in social and political spheres by lobbing public officials, joining political interest groups and participate in policymaking. 


\section{2.1 Informed consent}

In embryonic stem cell research consent must be gained from both female and male donors. The main ethical challenge that nurses face is not whether the patient is able to give informed consent but the extent to which the consent form reflects the nature of the trials rather than nature of the treatment procedure. The premise is that ESC research is presented as holding out the hope to alleviate the suffering to the extent that the person giving the consent may influence the giving of it. Furthermore, the desperate situations of patients make it easier for health worker to manipulate their opinions. The ethical rights of each patient group should be paramount in a health care environment. To guard couples going through IVF against intrusion or pressure from their doctor, it has been suggested that someone other than the doctor treating them should obtain the consent. This is because the patients' values may undergo subtle manipulation by staff. In obtaining consent for clinical trials, nurses and any health worker who obtains the consent must ensure the following; do a value clarification, be aware that their position of trust should not be in conflict with the patient's needs and be ready to support the final decision of the patients. Thus, returning autonomy to the patient through the process of empowerment.

There is also the issue of confidentiality. When tissue/eggs are donated, the donor usually remains anonymous, but can be traced through a code link to prove that the tissue was given with full consent. Conflict in confidentiality may occur in situations when embryo donated for research, carry genetic abnormalities or microbial infections unknown to the donor. It becomes more complicated if a recipient later contracts a disease that is linked to the tissue. The question arises as to whether the donor should be told? Morally it is expected that those receiving donated tissue have a right to know that it is as safe. In such situations the nurse will need special sensitivity in handling private and personal patient circumstances/issues to balance clinical need and ethical choices. This is an attempt to avoid conflict in confidentiality.

\subsubsection{Ensuring equal access to treatment}

Despite the sporadic achievement of IVF activity already underway in Nigeria, one hopes that the issue of accesses will be seriously considered given the country economic inequity and fragile healthcare structure. Chapman et al., [15] explained that "good access exists when patients can get the right service at the right time in the right place." An egalitarian approach implies that all persons should have accesses to innovative novel and cost-effective means of treating disease and IVF. But in reality some people may not benefit from ESR services through social circumstances, geographical location or other factors [15].The current cost of IVF in Nigeria may make the clinical uses of this technique to be limited to the very wealthy. The nurse employing the champion of social justice model of advocacy can eradicate this health care injustice and inequality by empowering the community on their right to care and calling attention of the government to inconsistency in the provision of health care resources at all levels. The responsibility to lessen this burden therefore rests with the Government playing a stewardship role to put up strategies to reduce out-ofpocket payments by removing public sector user fees, develop innovative ways to limit other health care costs (such as drug and transport cost), widen geographical access to health services and strengthening referral linkages.

\subsubsection{Protecting the rights of women}

While the embryonic stem cell debate has been pre-occupied with the clinical and ethical advantages and disadvantages of ES research, its social impacts in sustaining existing pattern of female oppression of the rights of women to their own eggs have been ignored. The argument here is that women who donate ova or embryos are at risk of exploitation in view of the huge financial benefit to medical practitioners who appropriates their reproductive labor for research and commercial benefits. Moreover, Robertson [2] argued that women's body parts are at risk of being commoditized, and their acts of altruistic donation demeaned, if downstream users can develop commercial applications for stem cells developed from their ova and embryos. Extending the argument Cedar [3] opined that women could be coerced into going through egg donation treatments to benefit sick relatives. Therefore, Nurses need to ensure the 'voluntary' contribution of women rather than their coercion to donate eggs. In this context the nurse represent those patients who have lost their power to represent themselves their needs, wishes, values and choices..

A related issue is the justification for financial incentive for women who donate eggs for research. Currently, there is a well-developed system for paying egg donors for infertility services. Logically, this should be extended to paying donors for eggs to be used in research as well. Yet there is great resistance for payment. This could be a grave issue for women in that, the procedure involves the injection of various compounds such as hormones, and can be an uncomfortable and intrusive. The argument here is that nurses must champion the course that women who donate eggs deserve to be paid for their efforts. The premise is that if a woman has had topay for IVF treatment, she is entitled to some financial recompense for the egg donation. 


\subsubsection{Regulation of clinical trial}

The nurse must collaborate with appropriate research agency to ensure adequate regulation of the research design of clinical trials. This is to minimize the risk to patients. In this context stringent measures must be put in place by the regulatory bodies (Medical and Dental Council of Nigeria, Nursing and Midwifery Council of Nigeria and other related council)in a collaborative effort to assess the integrity and potency of cell products. Pre-clinical data from animal model must be subjected to rigorous review. This is because the utility of animal models for some treatment with ESC research is limited. For example pharmaceutical agents that has been beneficial in non-human animal models for stroke has been found to be unsuccessful in human. These limitations on animal studies show the importance for a special body [12] to carefully look at and evaluate the pre-clinical data. In this regard the nurse must have adequate knowledge on the rudiments of ESR and clinical trials for her to make useful contributions.

\section{Conclusion}

In this paper attempts have been made to explore some of the ethical and socio-political issues arising from stem cell research in Nigeria. Stem cell research raises many ethical dilemmas, but the question is does the end really justify the means on this issue? Nigerians must evaluate the appropriateness of stem cell technologies within our own national contexts and systematically identify and prioritize which applications are the most promising for improving the health of Nigerians. Thus, it is suggested that Stem cell research in Nigeria should focus not only on IVF techniques but also on preventive and treatment options for non-communicable diseases (hypertension, diabetes mellitus, heart disease, sickle cell disease, cancers, mental health, blindness, and stroke) which constitute a major causes of mortality and morbidity in the country. Thus, nurses as advocate for the vulnerable (the fetus, the young, the elderly, and women) need to understand the biological processes of stem cell research, the ethical issues, research design and treatment. Nurses must be ready to explain the full implications of the procedures and the potential benefits and risks to patients. This information will be used to lead the patient to make informed decisions that are in accord with his or her own values and lifestyles.

\section{References}

[1] J. A. Robertson, Compensation and Egg Donation for Research Fertility and Sterility Vol 86 No 6 (2006); 1573-1575

[2] M. C. Nisbet, The Polls_-Trends: Public Opinion about Stem Cell Research and Human Cloning. Public Quarterly, 68, 24(2004). Retrieved October 29, 2010, From Expanded Academic ASAP Database.

[3] T.L. Beauchamp, \&J. F. Childress, Principles of Biomedical Ethics 3rdEd, Oxford University Press, 2000

[4] S.H. Cedar, Stem Cell and Related Therapies: Nurses and Midwives representing All Parties. Nursing Ethics 13 (3) (2006)

[5] L.J. Nelson, \&M.J. Megerui, Confronting Deep Moral Disagreement; The President Council On Bioethics Moral Status \& Human Embryo American Journal of Bioethics 5(6); 2005, 33-42 New York.

[6] R. Lanza, \&N.Rosenthal. The Stem Cell Challenge. Scientific American, 290, 2004, 92. Retrieved October 28, 2010, from Academic Search Premier database.

[7] FMOH, National Demographic and Health Survey (NDHS) report 2008.

[8] D.N. Irvin, Stem Cell Research: some pros and cons 1999.. Retrieved October 29, Retrieved October 29, 2009, from http://www.lifeissues.net/writers/irv/irv_19stemcellprocon.html

[9] K. Devolder, Creating and Sacrificing Embryos for Stem Cells, J Med Ethics 31: (2005) 366-/70

[10] R. O'Rahilly, \&F. Muller, Human Embryology \& Teratology Wiley-Liss, New York 1996.

[11] M. Ruiz-Canela, Embryonic Stem Cell Research; The Relevance of Ethics In The Progress of Science Med. Sci Monit, 8 (50) 2002,21-26.

[12] National Research Council 'Guideline for Human Embryonic Stem Research' 2005 Available at $<$ http;//www.nap.edu/catalog id=11278 Retrieved April 28, 2010

[13] Www.stemcllglobalblueprint.net retrieved October 62011.

[14] FMOH National Strategic Health Development Plan (NSHDP, 2010-2015) (2010)

[15] WHO Preventing Chronic Diseases; A Vital Investment Geneva, Switzerland; WHO Press, 2005

[16] Chapman, J. L., Zechel, A., Carter, Y. H. \& Abbott, S. . Systematic Review of RecentInnovation In Service Provision To Improve Access To Primary Care. British Journal OfGeneral Practice. 54(502), (2004) 374-381. 